\title{
DO CONTRASSENSO TEÓRICO
}

AOS PERIGOS PARA A HUMANIDADE EUROPEIA: A CRÍTICA DE HUSSERL À NATURALIZAÇÃo

DA CONSCIÊNCIA

\begin{abstract}
[FROM THE THEORETICAL MISUNDERSTANDING TO THE DANGERS FOR EUROPEAN HUMANITY: HUSSERL'S CRITICISM TO THE NATURALIZATION OF CONSCIOUSNESS]
\end{abstract}

Carlos Diógenes Côrtes Tourinho

Universidade Federal Fluminense

DOI: http://dx.doi.org/10.21680/1983-2109.2016v23n42ID9694

Natal, v. 23, n. 42

Set.-Dez. 2016, p. 151-174

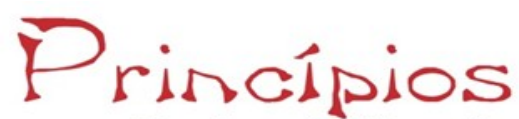

Revista de filosofia E-ISSN: 1983-2109 
Resumo: O presente artigo aborda a crítica de Husserl ao projeto de naturalização da consciência. $\mathrm{O}$ artigo está dividido em duas partes principais: a primeira parte aborda o contrassenso teórico deste projeto, ao passo que a segunda parte trata dos perigos que este projeto representa para a cultura e, em especial, para a formação da mentalidade do homem europeu. Tal mundaça de foco permitirá a Husserl, a partir da década de 30, analisar a "crise espiritual" vivida pela humanidade europeia.

Palavras-chave: Edmund Husserl; Naturalismo; Cultura; Fundamentos; Crise; Humanidade.

Abstract: The present paper approaches Husserl's criticism to the project of naturalization of consciousness. The article is divided in two principal parts: the first part discusses the theoretical misunderstandings of this project, whereas the second part approaches the dangers that this project represent for the culture and in particular to the formation of the European man mentality. The new focus will allow to Husserl, since the 30s, analyze the "spiritual crisis" experienced by European humanity.

Keywords: Edmund Husserl; Naturalism; Culture; Foundations; Crisis; Humanity. 
Se considerarmos o itinerário de Edmund Husserl no século XX, ao menos, examinando o seu percurso de 1900 a 1911, é possível notar uma preocupação renovada do autor em afirmar a tese segundo a qual toda tentativa de fundamentação da Matemática, da Lógica, ou mesmo, da prória Filosofia, em um pensamento que tenha como base a doutrina do naturalismo - segundo a qual pensar o mundo consiste em pensá-lo unicamente como uma realidade de fatos naturais - leva-nos, inevitavelmente, a um "contrassenso teórico" e, por conseguinte, a um ceticismo que se autocontradiz. Afinal de contas, como nos mostra Husserl desde 1900, em Prolegômenos à lógica pura (Prolegomena zur reinen Logik), ao ignorar a distinção entre o ato psicológico de pensar e o conteúdo ideal do pensamento, tomando indevidamente o segundo em termos do primeiro, reduzindo, com isso, o próprio conteúdo do pensamento a uma realidade de fatos naturais, além de incorrer em problemas de fundamentos, tal modo de consideração natural confina o homem - enquanto ente psicofísico - a uma relação meramente empírica com o mundo. Neste caso, por mais êxito que o pensamento obtenha, fica confinado a inferir, a partir da observação dos fatos, proposições que não são senão generalizações da experiência, não perdendo, por conseguinte, o seu cariz episódico ou contingente. Tais proposições inferidas nos levariam, inevitavelmente, segundo Husserl, uma vez que as mesmas careceriam de validade apodítica, a um relativismo cético. E se afirmarmos, em conformidade com o pensamento natural, a tese segundo a qual "todas" as proposições inferidas pelo pensamento são generalizações da experiência e, por isso, na medida em que carecem de validade absoluta, são proposições passíveis de questionamento, estaremos supondo, ao menos, que a própria tese afirmada é uma "excessão" à regra. Eis, aos olhos de Husserl, o contrassenso do qual a consideração naturalista não se apercebe.

Portanto, desde 1900, em Prolegômenos, passando pelas "Cinco Lições" (Fünf Vorlesungen) de 1907, até o artigo publicado em 1911 para a Revista Logos, intitulado "Filosofia como ciência de 
rigor" ("Philosophie als strenge Wissenschaft"), Husserl não mede esforços em denunciar a implicação cética da aceitação do modo de consideração natural perante o mundo. Se tomado como base para a fundamentação das leis do pensamento, tal modo de consideração incorreria, conforme vimos acima, em problemas de fundamentos, ao insistir, como se nota, especificamente, em Prolegômenos, no propósito de fundamentar a Lógica na Psicologia (entendida aqui como "ciência empírica"), considerando o "real" e o "ideal" em um só domínio, ao invés de situá-los em domínios distintos (isto é, ao invés de considerar, conforme acentuam os lógicos normativos, tais como, Herbart, Hamilton, dentre outros, a distinção entre o "pensar como ele é" e o "pensar como deve ser") ${ }^{1}$.

Tomado pelo anseio incansável de reeditar, no século $\mathrm{XX}$, o projeto de fundamentação da filosofia como uma "ciência rigorosa" (strenge Wissenschaft) - intenção primária que acompanha o itinerário husserliano por quase quatro décadas ${ }^{2}$ - Husserl não hesita em chamar à atenção do leitor para os riscos de se levar adiante o propósito de fundamentar a filosofia em um naturalismo, esvaindo-a em uma realidade de fatos naturais. Mais do que nunca, tal preocupação visa, primeiramente, denunciar o contrassenso teórico a que tal propósito nos conduz, visando, assim, afastar o projeto de

\footnotetext{
${ }^{1}$ No Terceiro Capítulo, especificamente no §19, Husserl lembra-nos de que os partidários do que poderíamos chamar de um "antipsicologismo logicista", adeptos de uma lógica formal e demonstrativa (tais como, Herbart, Hamilton, dentre outros) não deixam de fundamentar uma separação rigorosa entre os domínios da lógica e da psicologia. Neste sentido, contestam toda tentativa de fundamentação da lógica na psicologia, bem como da concepção da lógica como uma "técnica do pensar", afirmando-nos que a psicologia considera o pensar como acontece, isto é, como ele é (enquanto ato psíquico), ao passo que a lógica considera o pensar como deve ser. Cf. Husserl, [1900] 1913, p. 53.

${ }^{2}$ Alexandre Fradique Morujão lembra-nos de que: "Das Investigações Lógicas a Crise das Ciências Europeias e a Fenomenologia Transcendental, uma intenção primária dá corpo e articula os sucessivos trabalhos de Husserl, inéditos ou não. Podemos definir esse denominador comum como a exigência da filosofia como ciência rigorosa". Cf. Morujão, 2002, p. 147.
} 
fundamentação da filosofia de um caminho que incorresse na naturalização do pensamento. Afinal, como o próprio autor esclarece, desde Prolegômenos, não podemos conferir à verdade um "caráter de fato". Eis uma preocupação que se renova em Husserl, ano após ano, ao longo da primeira década do século XX, período no qual vigora um ideal positivista de ciência, cujas bases repousam justamente na doutrina do naturalismo.

Mas, se durante o referido período do itinerário husserliano, é devido a problemas de fundamentos que Husserl é levado a denunciar o contrassenso teórico produzido pelo projeto de naturalização da consciência (Naturalisierung des Bewußtseins), ou mesmo, nos termos do artigo de 1911, de "naturalização das ideias" (Naturalisierung der Ideen), a partir deste período, cada vez mais, nota-se uma preocupação por parte do autor em denunciar os riscos que a realização de tal projeto naturalista teria para a formação da mentalidade do homem europeu. Trata-se de uma preocupação que irá, pouco a pouco, se acentuar no itinerário husserliano. $\mathrm{O}$ primeiro sinal desta nova preocupação já pode ser notado em "A filosofia como ciência de rigor" (1911), artigo no qual Husserl nos chama à atenção para o perigo crescente que o naturalismo representa para a cultura. Se em tal artigo, a referida observação não tem maiores desdobramentos, ela já indica, por si só, uma nova preocupação do autor: além dos problemas de fundamentos nos quais o naturalismo - em seu projeto de naturalização da consciência - incorre, caberá também alertar para os impactos que tal modo de consideração natural do mundo teria para a formação da mentalidade do homem europeu, com graves consequências para a cultura europeia.

Mas é a partir da década de 20 que tal preocupação começa a ganhar contorno mais nítido. A série dos artigos publicados para a revista japonesa Kaizo, de 1923 a 1924, em especial, o primeiro artigo da série - intitulado "Renovação. Seu problema e seu método" ("Erneuerung. Ihr Problem und ihre Methode") - irá evidenciar esta preocupação por parte do autor. Os sinais da crise do ho- 
mem europeu estariam relacionados, segundo Husserl, a não realização de uma "mathesis do espírito e da humanidade", tal como a humanidade europeia se emprenhou em realizar, com base na matemática pura, uma nova ciência da natureza, desde as origens do Mundo Moderno. Mas, é na década de 30 que, enfim, assistimos Husserl proferir, em 1935, a famosa conferência de Viena sobre $A$ crise da humanidade europeia e a filosofia (Die Krisis des europäischen Menschentums und die Philosophie). Nela, Husserl propõe um diagnóstico da etiologia do adoecimento da vida espiritual da Europa. A consolidação de um projeto de naturalização da consciência - com os seus respectivos problemas de fundamentos, para os quais o autor já chamava à atenção desde a virada do século XIX para o século XX - fomentou, na formação da mentalidade europeia, um esquecimento daquilo que nos remeteria, segundo a análise husserliana, para o sentido mais originário da vida espiritual do homem europeu: o surgimento da filosofia, enquanto uma nova forma cultural, tal como os gregos a pensaram. Eis, aos olhos de Husserl, a causa maior da crise da humanidade europeia.

O presente artigo concentrar-se-á, portanto, em torno do seguinte objetivo: mostrar para o leitor como que a crítica de Husserl ao projeto de naturalização da consciência passará, com o decorrer dos anos, sobretudo, a partir da experiência da Primeira Guerra, por uma mudança de foco. Se num primeiro momento, especificamente, de 1900 a 1911, a preocupação maior de Husserl recai sobre a denúncia dos problemas de fundamentos nos quais incorre o projeto de naturalização da consciência, num segundo momento, ao final da segunda década e, efetivamente, a partir da década de 20, o autor alerta-nos, sem perder de vista a denuncia feita no período anterior, para os perigos crescentes que o naturalismo representa para a cultura e, em especial, para a formação da mentalidade do homem europeu. Tal mundaça de foco permitirá a Husserl diagnosticar, a partir da década de 30, a "enfermidade espiritual" vivida pela humanidade europeia, desde a Primeira Guerra. 
O tema abordado será dividido, grosso modo, em duas partes. Na primeira delas, o artigo abordará o período de 1900 a 1911, percorrendo três momentos principais da denúncia apresentada por Husserl quanto aos problemas de fundamentos nos quais incorreria, inevitavelmente, o modo de consideração natural do mundo adotado para a fundamentação das leis do pensamento: 1) a crítica de Husserl ao psicologismo em Prolegômenos; 2) a tarefa crítica da teoria do conhecimento nas "Cinco Lições" de 1907; 3) a crítica ao naturalismo em "A filosofia como Ciência de Rigor" (1911). Na segunda parte, o artigo mostrará como que, aos poucos, ao longo da segunda década do século XX, Husserl começa a despertar, em suas reflexões, mais explicitamente, para uma perspectiva "político social", ao denunciar, sem ignorar os problemas de fundamentos anteriormente levantados, os impactos produzidos pelo referido projeto naturalista sobre a cultura. Destacar-se-ão dois momentos principais: 1) contra os "preconceitos naturalistas" e frente à crise do Ocidente europeu, o manifesto husserliano em favor de uma "renovação" (Erneuerung), cujo fim visasse à realização de uma reforma racional da cultura, no primeiro artigo publicado por Husserl para a revista japonesa Kaizo, em 1923; 2) o diagnóstico husserliano da crise vivida pela Europa, apresentado publicamente em Viena, em 1935, em A crise da humanidade europeia e a filosofia. Passemos, então, a um exame pormenorizado das denúncias feitas por Husserl contra o projeto de naturalização da consciência: do contrassenso teorético que lhe é implicito aos perigos que a consolidação do referido projeto representa para a cultura europeia. Vejamos.

\section{O contrassenso teórico e os problemas de fundamento inerentes ao modo de consideração natural: de 1900 a 1911}

O ponto de partida da crítica de Husserl ao projeto de naturaização do pensamento leva-nos, primeiramente, ao volume introdutório da primeira edição de Investigações Lógicas. Enquanto volu- 
me propedêutico à referida obra, "Prolegômenos à Lógica Pura" texto elaborado em 1899, resultante de lições proferidas em Halle em 1896, mas somente publicado em 1900 - é comumente lembrado como um marco no itinerário husserliano, justamente porque se trata de uma obra ao longo da qual Husserl se concentra, fundamentalmente, em torno da crítica ao psicologismo (mais precisamente, em torno da pretensão - difundida no último quarto do século XIX - de fundamentação da Lógica na Psicologia). Trata-se, portanto, de uma crítica que recai sobre "problemas de fundamentos". Afinal, ao anunciar, para usar os termos de Theodor Lipps (1880), uma "física do pensar" (Physik des Denkens) ${ }^{3}$, a abordagem psicologística confundiria o ato psicológico de pensar com o conteúdo ideal do pensamento e, portanto, o real com o ideal. Entre os psicologistas do final do século XIX, tais como Theodor Lipps, Wilhem Wundt, Stuart Mill, dentre outros, prevalece a conviç̧ão segundo a qual os fundamentos da Lógica encontram-se na própria Psicologia, de maneira que a Lógica - concebida por tais autores não como uma disciplina meramente formal e demonstrativa, mas sim, como uma "técnica do pensar" (l'art de penser) consistiria apenas em uma parte ou ramo da ciência psicológica. Em tal concepção psicologista, caberia à Psicologia fornecer o fundamento teórico para a construção de uma técnica lógica e, de acordo com tal concepção, jamais se poderia afastar da Lógica o seu conteúdo psicológico, de modo que tal conteúdo já estaria presente nos conceitos de "verdade" e "falsidade", "afirmação" e "negação", e assim por diante.

Se nos voltarmos para o Quarto Capítulo de "Prolegômenos", em especial, para o §21, constataremos Husserl nos chamando a atenção para o seguinte ponto: enquanto "ciência de fatos", que se ocupa com fatos (matter of fact) e, portanto, enquanto "ciência experimental", a Psicologia - ao modo de consideração das ciên-

\footnotetext{
${ }^{3}$ Lipps afirma-nos que: "A Lógica é física do pensar ou ela não é nada" ("Die Logik ist Physik des Denkens oder sie ist überhaupt nichts"). Cf. Husserl, [1900] 1913, §19, p. 55.
} 
cias positivas - adota a indução como método de investigação. Procede habitualmente por observação sistematizada de fatos particulares procurando descrever a regularidade do que é observado para inferir, então, indutivamente, o que os cientistas positivistas denominam de "leis gerais". Husserl esforça-se em mostrar que, enquanto regras meramente empíricas (isto é, "aproximativas"), inferidas através da indução exercida pela ciência psicológica, tais "leis gerais" carecem de exatidão absoluta, pois a validade dessas leis depende de "circunstâncias" e, deste modo, não são "leis" no sentido autêntico da palavra. Embora muito valiosas, não são mais do que "generalizações vagas da experiência" (vage Verallgemeinerungen der Erfahrung). Para Husserl, todas as leis alcançadas por indução consistem, na medida em que carecem de validade absoluta, em "leis de probabilidade". A propósito de tais regras empíricas, recordemo-nos ainda do que Husserl nos diz, no §21 de Prolegômenos: "sobre fundamentos teoréticos vagos só podemos fundar regras vagas" (Husserl, [1900] 1913, §21, p. 61). Neste sentido, essas mesmas leis psicológicas - tais como, por exemplo, as leis de associação de ideias ("semelhança", "contiguidade" e "causa e efeito") - não poderiam ser confundidas com as leis da lógica (os princípios lógicos como o "princípio de não contradição", as leis da silogística etc.), cuja validade é a priori, cuja fundamentação e justificação se dão não por meio da indução, mas por evidências apodíticas apreendidas por intelecção. Daí Husserl dizer, no Quarto Capítulo de Prolegômenos, no §21, que: "a probabilidade não pode se impor contra a verdade, ou a conjectura contra a intelecção" (Husserl, [1900] 1913, §21, p. 64).

Husserl deixa-nos claro que, ao identificar as leis do conteúdo do ato com as leis que regulam o processo psicológico, os psicologistas acabam por fazer com que a verdade que constitui o conteúdo do ato dependa diretamente do processo psíquico, isto é, da constituição da natureza humana, o que inevitavelmente levar-nosia a afirmar que tal verdade não existiria se não existisse essa constituição. Conforme Husserl esclarecerá no Sétimo Capítulo, 
especificamente no §36: "O que é verdadeiro é absolutamente verdadeiro, é 'em si' verdadeiro" (Husserl, [1900] 1913, §36, p. 117). Husserl nos lembrará, no mesmo parágrafo, que a constituição da espécie humana é um fato e a partir de fatos somente podemos derivar "fatos". Por conseguinte, toda tentativa de fundar a verdade sobre tal constituição implicaria em conferir à verdade um "caráter de fato", o que seria, para Husserl, um contrassenso, uma vez que todo fato é individual e, portanto, temporalmente determinado; já a "verdade em si" é supraempírica e, portanto, a propósito dela mesma não faria sentido algum atribuir o discurso de uma determinação temporal. Como o próprio autor faz questão de ressaltar no mesmo parágrafo: "Pensar verdades como causas ou efeitos é um absurdo" (Husserl, [1900] 1913, §36, p. 117). Vê-se, portanto, a preocupação de Husserl em fazer com que, já a partir do texto de Prolegômenos, o leitor perceba que a verdade não poderia, de maneira alguma, depender - como querem os psicologistas - da constituição da natureza humana, pois, tal dependência abalaria o próprio sentido da ideia de verdade ${ }^{4}$.

Cerca de sete anos após a publicação de Prolegômenos, resultado das lições proferidas por Husserl em abril-maio de 1907, em Göttingen, as chamadas "Cinco Lições" (Fünf Vorlesungen) - publicadas, em 1950, sob o título de A Ideia da Fenomenologia (Die Idee der Phänomenologie) - denunciam o contrassenso inerente ao pensamento natural em relação à possibilidade do conhecimento. Na primeira das cinco lições, Husserl afirma-nos que o modo de consideração natural perante o mundo, denominado por ele de "atitude espiritual natural" (natürlichen Geisteshaltung) - adotado habitualmente pelos homens, bem como pelas ciências positivas da natureza - considera o conhecimento como uma "obviedade". Como Husserl nos diz, logo na Primeira Lição: "É evidente para o pensamento natural a possibilidade do conhecimento" (Husserl, [1907]

${ }^{4}$ Sobre o uso, bem como as implicações da ideia de "verdade" em Prolegômenos, cf. Tourinho (2014). 
1950, p. 19). Pode-se dizer que tal modo de consideração encontra-se apoiado na doutrina do naturalismo, para a qual pensar o mundo consiste em pensá-lo como uma realidade de fatos naturais, na qual o homem (como ente psicofísico) estaria confinado a uma relação meramente empírica com os demais entes que habitam o seu mundo circundante. Ao adotar tal atitude, caberia, ao homem de ciência, em uma vivência supostamente cognoscitiva, observar sistematicamente o fenômeno positivo, descrever a sua regularidade, para inferir, enfim, uma generalização empírica. Conforme Husserl esclarece, mergulhada no pensamento natural (Natürliches Denken), a ciência dita "positiva" mostra-se despreocupada quanto às dificuldades da possibilidade do conhecimento, pois, a mesma considera como óbvia tal possibilidade. Pode-se dizer, com isso, que a referida ciência manifesta, do ponto de vista filosófico, uma ingenuidade no realismo que adota frente ao objeto que investiga, uma vez que a mesma não se interroga pelo sentido da objetividade que ela própria considera como dada, ou como inquestionável. Deste modo, "dá às costas" para a filosofia e, em particular, para a questão colocada pela teoria do conhecimento: afinal, em que se fundamenta a suposta relação de correspondência entre a vivência dita "cognoscitiva" e as coisas que lhe são transcendentes? O que o pensamento natural considera como "óbvio" e livre de questionamentos, a reflexão - exercida sobre a relação da vivência cognoscitiva com o que lhe é transcendente - revela-nos como um "enigma", designado por Husserl de "enigma do conhecimento natural" (Rätsel der natürlichen Erkenntnis), colocandonos, assim, frente a frente, com a questão ignorada pelo pensamento natural adotado pelas ciências.

Abrem-se as portas para o exercício da "tarefa crítica" da teoria do conhecimento, cujo propósito será o de denunciar o contrassenso a que nos conduz o ceticismo em relação à temática do conhecimento. $\mathrm{O}$ exercício de tal tarefa permite-nos, inicialmente, identificar que, ao ignorar o caráter "enigmático" do conhecimento transcendente, a posição assumida pelas ciências naturais implica 
em um ceticismo obscuro (ou "não declarado"), na medida em que se torna inapercebido por tais ciências. Ao conceber o mundo como uma realidade de fatos naturais, considerando inclusive o próprio pensamento como um "fato natural" (colapsando a distinção necessária entre o ato psicológico de pensar e o conteúdo ideal do pensamento, o que, por si só, nos conduz a problemas de fundamentos, conforme Husserl já alertava desde Prolegômenos), o pensamento natural confina-nos a uma relação meramente empírica com as coisas, através da qual inferimos generalizações empíricas. Assim, em tal atitude, por mais êxito que o pensamento obtenha em operar tais inferências a partir da observação sistematizada de fatos, fica confinado a proposições cuja validade se torna meramente empírica e que, enquanto tais, não perdem o seu caráter "contingente", não nos livrando, por conseguinte, do assédio da dúvida e do que não é inteiramente evidente. Há, portanto, em tal modo de consideração natural, um ceticismo iminente. Se afirmarmos, em conformidade com o pensamento natural, a tese segundo a qual "todas" as proposições inferidas pelo pensamento são generalizações da experiência e, por isso, na medida em que carecem de validade absoluta, são proposições passíveis de questionamento, estaremos supondo, ao menos, que a própria tese afirmada é uma "excessão" à regra. Eis o que permanece desconhecido pelas ciências naturais e, ao mesmo tempo, denunciado pela tarefa crítica da teoria do conhecimento: o contrassenso a que nos conduz o ceticismo inerente ao pensamento natural adotado por tais ciências.

Quatro anos depois, em 1911, em seu artigo publicado para o primeiro volume da Revista Logos, intitulado "Filosofia como Ciência de Rigor" ("Philosophie als strenge Wissenschaft"), especificamente na primeira parte do artigo, Husserl volta a denunciar o contrassenso do modo de consideração natural perante o mundo, bem como os problemas de fundamentos inerentes ao projeto de naturalização da consciência. Trata-se dos reflexos de uma crítica anunciada dez anos antes em Prolegômenos. Já no começo da pri- 
meira parte do referido artigo, intitulado "Filosofia Naturalística" (Naturalistische Philosophie), Husserl afirma-nos que "o cientista dedicado às ciências naturais tende a considerar tudo como natural" (Husserl, 1911, p. 294). Apoiado na doutrina naturalista, tal cientista mantém firme a sua crença de que não se depara senão com a natureza, a começar com a natureza física. O autor nos diz que, para o naturalista: "Tudo o que é, ou é propriamente físico [...] ou se for psíquico, é mera variação dependente do físico" (Husserl, 1911, p. 294). Para Husserl, em sua forma extrema, o naturalismo resulta, então, por um lado, em uma "naturalização da consciência" (Naturalisierung des Bewußtseins), incluindo todos os dados intencionais e imanentes da consciência e, por outro lado, em uma "naturalização das ideias" (Naturalisierung des Ideen), e de todos os ideais e normas absolutos. Em sua versão extrema, conforme Husserl já apontava desde Prolegômenos, o naturalismo considera todos os princípios lógicoformais, as chamadas "leis do pensamento", em termos de leis naturais do pensamento (incorrendo, com isso, no contrassenso de confundir o ato de pensar com o coenteúdo ideal do pensamento). Conforme Husserl já havia também denunciado nas "Cinco Lições" de 1907, o contrassenso que resulta do modo de consideração naturalista, segundo o qual pensar o mundo consiste em pensá-lo unicamente como uma realidade de fatos naturais, manter-se-ía "obscuro" para o cientista natural porque ele próprio não se aperceberia do caráter infundado de sua posição. Nos termos de Husserl: "O contrassenso que se encontra nele não é manifesto, mas se oculta a ele próprio" (Husserl, 1911, p. 295-296). O autor é categórico em afirmar, ainda na primeira parte do artigo de 1911, a propósito desta "cegueira naturalista", que: "Os preconceitos cegam, e quem apenas vê fatos empíricos e intimamente atribui valor somente à ciência empírica, não se sentirá muito abalado com consequências absurdas que não podem ser comprovadas empiricamente como contraditórias com os fatos da Natureza. Irá desprezá-las como mero 'Escolasticismo"' (Husserl, 1911, p. 296). 
Para Husserl, absorvido por esta "cegueira", se o naturalista tende a considerar os argumentos que apontam para o contrassenso inerente à sua posição como argumentos meramente "escolásticos", é na medida em que, do ponto de vista filosófico: "Toda ciência natural é ingênua pelos seus pontos de partida" (Husserl, 1911, p. 298). Se até então, tal ingenuidade estaria relacionada ao que impede o próprio naturalista de notar os problemas de fundamentos nos quais a sua posição incorre, Husserl começa, ao poucos, já a partir do artigo de 1911, a chamar à atenção do leitor para os perigos desta ingenuidade, uma vez que o contrassenso teórico no qual incorre a posição naturalista seria seguido por um contrassenso ético-social. Nos termos do autor, "os contrassensos teóricos são inevitavelmente seguidos por contrassensos (discordâncias evidentes) no procedimento atual, teórico, axiológico, ético" (Husserl, 1911, p. 295). Em seguida, o mesmo autor nos diz ainda: "O Naturalista é doutrinador, pregador, moralizador, reformador". Por fim, a passagem que talvez melhor indique uma nova preocupação de Husserl pode ser encontrada ao final da introdução do famoso artigo de 1911, na qual o autor nos diz que o naturalismo dominante na Europa "significa praticamente um perigo crescente para a nossa cultura" (Husserl, 1911, p. 293). Mas, o que Husserl estaria querendo, ao certo, dizer com tal afirmação? É o que examinaremos a partir de agora.

\section{Os perigos do naturalismo para a humanidade europeia: o artigo de 1923 para a Revista Kaizo e a conferência de Viena de 1935}

Apesar das indicações do artigo de 1911, pode-se dizer que as reflexões husserlianas sobre a cultura e, em particular, sobre a crise do Ocidente, ganham contornos mais nítidos nas décadas de 20 e de 30. No entanto, tais reflexões parecem, inicialmente, se acentuar por ocasião da Primeira Guerra, cujas consequências foram catastróficas para a Europa no seu todo e, no plano pessoal, foram dramáticas para Husserl. Afinal, se a declaração da guerra, 
em 1914, aparentemente, não promove mudanças significativas na vida universitária de Husserl, por outro lado, a guerra não deixa de atingir o seu círculo de colaboradores, dispersando os seus membros mais jovens. Apesar de Husserl continuar seus cursos e seminários - uma vez que, com 55 anos, encontra-se livre de qualquer obrigação militar - seus dois filhos incorporam-se em 1914 e sua filha Elisabeth alista-se como enfermeira. Os anos seguintes já reservariam a Husserl as mais duras provações: o filho mais novo, Wolfgang, é ferido e, em 1916, cai no forte Vaux; o mais velho, Gerhart, é, por sua vez, gravemente ferido no ano seguinte; em 1917, o seu discípulo e amigo A. Reinach é morto na frente. Husserl retrai-se, durante um ano, no silêncio, e chega mesmo a declarar, a seu amigo Albrecht, que: "como é duro ter que perder os entes mais queridos e mais fiéis; sinto uma terrível nostalgia do repouso que constituirá a conclusão natural de nossa existência terrestre" (Kelkel; Schérer, 1964, p. 10). Husserl é, portanto, a esta altura, um homem profundamente amargurado. "Mas, se o indivíduo está ferido, o filósofo - que concebe a sua missão como aquela de um 'funcionário da humanidade' - deve se elevar acima de seu sofrimento e das contingências da história" (Delacampagne, 1995, p. 46).

A partir da década de 20, evidencia-se a preocupação de Husserl em dar o seu parecer a respeito da crise da Europa, propondonos, ao mesmo tempo, uma reforma racional da cultura que pudesse, em meio à crise, conduzir a humanidade europeia em direção a uma humanitas autêntica, através da realização de uma genuína ciência do espírito, inviabilizada, segundo o próprio autor, por "preconceitos naturalistas" (naturalistische Vorurteile). Husserl afirma-nos, logo no primeiro dos seus artigos publicados pela revista japonesa Kaizo, intitulado "Renovação: seu problema e seu método" ("Erneuerung. Ihr Problem und ihre Methode"), de 1923, que a Europa está em crise e, em seu doloroso presente: "algo novo deve suceder" (Husserl, [1923] 1989, p. 4), em nós e através de nós próprios, enquanto membros da humanidade vivendo neste 
mundo. Faz-se necessário promover, então, segundo Husserl, uma "renovação" (Erneuerung) em meio a esta humanidade europeia devastada pela guerra. Afinal, esta mesma humanidade que se orgulhava do ideário positivista de ciência desde o último quarto do século XIX e, por conseguinte, de ter alcançado um estágio positivo, supostamente "mais avançado" numa linha progressiva, começava a dar sinais de declínio a partir da Primeira Guerra, revelando, de acordo Husserl, a sua "ausência de sentido". Nos termos do autor: "Se ela já tinha se tornado vacilante antes da guerra, desmoronou-se agora completamente" (Husserl, [1923] 1989, p. 4). Daí a formulação husserliana da questão, em tom de manifesto: será que deveremos aguardar para ver se esta cultura não sana a partir de si própria, num mero jogo de sorte entre as suas forças produtoras e destruidoras de valores? E ainda: "Deveremos considerar a 'decadência do Ocidente' como um factum que se abate sobre nós?” (Husserl, [1923] 1989, p. 4). A humanidade europeia estaria, então, com a guerra, condenada a se desorientar por um pessimismo fatídico e por um "realismo" sem ideais? Mas, pergunta-nos Husserl: e se agíssemos racionalmente? A racionalidade e a excelência não seria um caminho possível para remediar essa crise? Certamente, se esta crise não fosse marcada por uma perda da crença - "que nos elevou, a nós e a nossos pais, e que foi transmitida às nações" (Husserl, [1923] 1989, p. 3) - na racionalidade e na excelência de sermos um membro importante de tal humanidade, de colaborarmos com tal cultura, de contribuirmos para os seus valores exaltantes, etc. Eis, segundo Husserl, "o estatuto de todos aqueles que são excelentes, a qual os eleva acima das suas preocupações e infortúnios individuais" (Husserl, [1923] 1989, p. 3). Se por um lado, a almejada reforma da cultura implica na retomada desta crença, por outro lado, o principal obstáculo a ser superado se encontra na figura dos homens que, absorvidos pela visão pessimista, não hesitam em considerar a retomada da referida crença - tanto no plano individual quanto em nível nacional - como um “objetivo quimérico” (chimärisch Ziel). 
Contra a visão pessimista segundo a qual a humanidade seria reduzida a uma "humanidade de fatos", contra a perda da crença na possibilidade da racionalidade e da excelência, Husserl aposta suas fichas em uma reforma racional da cultura. Nos termos do autor, trata-se de reacender: "A crença que nos preenche - que à nossa cultura não é permitido se dar por satisfeita, que ela pode e deve se tornar reformada através da razão e da vontade humanas" (Husserl, [1923] 1989, p. 5). Ao anunciar tal aspiração reformista, Husserl indica-nos que a crise que se abateu sobre a Europa seria decorrente da falta por completo de uma ciência racional do homem e da comunidade humana: "falta-nos a ciência que tivesse empreendido a realização para a ideia de homem e, com isso, também para o par de ideias inseparáveis: homem singular (Einzelmensch) e comunidade (Gemeinschaft)" (Husserl, [1923] 1989, p. 6). Os sinais desta crise do homem europeu estariam relacionados, portanto, segundo Husserl, a não realização de uma genuína "ciência do espírito" (ou de uma "mathesis do espírito e da humanidade"), tal como a humanidade europeia se emprenhou em realizar, com base na matemática pura, uma nova ciência da natureza, a partir do Mundo Moderno. Tomada por "preconceitos naturalistas" (naturalistische Vorurteile), tal humanidade - cuja existência seria, cada vez mais, atravessada pela descrença na racionalidade e na excelência - não perceberia a íntima relação entre os preconceitos do naturalismo e o estado de desamparo e de impotência que passou a tomar conta do homem europeu em meio ao cenário devastador da guerra.

É preciso lembrar ainda que, impulsionados pelo ideário positivista de ciência, alguns dos principais círculos acadêmicos europeus, desde o último quarto do século XIX, não hesitaram em considerar a realidade espiritual nos moldes das ciências naturais, considerando a consciência como "anexo externo" das realidades físicas (dos respectivos corpos físicos); considerando, enfim, "homens e animais como simples acontecimentos no espaço, 'na natureza"' (Husserl, [1923] 1989, p. 8). Tal inclinação naturalista não 
hesitaria, portanto, nos moldes das ciências positivas da natureza, em levar adiante o projeto de naturalização da "vida do espírito", tratando, deste modo, essa mesma vida espiritual em termos de uma realidade espacializante. Exercendo um papel preponderante na formação da mentalidade do homem europeu, o pensamento natural desconsideraria, enfim, a distinção essencial, bem como as relações, entre as realidades natural e espiritual. Daí Husserl dizer que procurar realizar uma ciência da realidade espiritual, ao modo de uma psicologia naturalista, a partir de uma abordagem indutivo-causal, seria um contrassenso, por todos os problemas de fundamentos nos quais tal intenção incorreria.

Ao denunciar tal contrassenso, a aspiração por uma reforma racional da cultura deveria abrir os caminhos obstruídos pelos preconceitos naturalistas. Por esse motivo, tal reforma constituirse-ía, antes de tudo, como uma aspiração que visa "reformar a cultura fática", reformar uma visão de mundo que confina os homens a juízos dirigidos para "simples fatos de existência". Só assim, superando tais preconceitos, a humanidade europeia poderia, segundo Husserl, ser recolocada no caminho de uma humanidade verdadeira e autêntica. Se o artigo de 1923 atesta claramente uma preocupação de Husserl em denunciar os perigos do pensamento natural para a cultura europeia, é a partir da década de 30 que tal preocupação se evidencia, claramente, no itinerário husserliano.

Convidado pelo Kulturbund vienense, em maio de 1935, Husserl profere a famosa conferência de Viena, intitulada $A$ crise $d a$ humanidade europeia e a filosofia (Die Krisis des europäischen Menschentums und die Philosophie). Nela, Husserl busca uma elucidação das origens mais profundas do adoecimento da vida espiritual da Europa: "As nações europeias estão enfermas. Diz-se que a própria Europa está em uma crise" (Husserl, [1936] 1976, p. 315). A consolidação de um projeto de naturalização do espírito - com os seus respectivos problemas de fundamentos, para os quais o autor já chamava à atenção desde a virada do século XIX para o 
século XX - fomentou, na formação da mentalidade europeia, um esquecimento daquilo que nos remeteria para o sentido mais originário da vida espiritual do homem europeu, para o que Husserl considera a "estrutura espiritual" (gestige Gestalt) da Europa: o surgimento da filosofia, enquanto uma nova forma cultural, cujo sentido original remete-nos para ideia de uma "ciência universal, a ciência da totalidade do mundo, da unidade total de tudo o que é" (Husserl, [1936] 1976, p. 321). Nos termos de Husserl: "Na irrupção da filosofia neste sentido, na qual todas as ciências estão incluídas [...] vejo o fenômeno originário da Europa espiritual" (Husserl, [1936] 1976, p. 321). A nova forma cultural conduz os homens, por meio de um "novo tipo de atitude" (neuartige Einstellung), a um deslocamento do olhar de suas metas finitas e circunstanciais, próprias de suas preocupações diárias inerentes a um "mundo circundante" (Umwelt), para metas ou tarefas infinitas ("o interesse pelo todo e, com isso, a pergunta pelo devir que engloba todas as coisas") (Husserl, [1936] 1976, p. 321), transformandoos, assim, em um novo homem: espectador desinteressado e contemplador do mundo. Com este novo homem, deparamo-nos, portanto, com uma mudança radical de atitude, cuja marca consiste em um puro interesse pelo conhecimento que, aos olhos de Husserl, já designa um interesse puramente teórico. Trata-se da decisão deste novo homem de consagrar toda a sua vida futura à teoria, de dar a ela um caráter universal, construindo "conhecimento teórico sobre conhecimento teórico in infinitum" (Husserl, [1936] 1976, p. 332).

Tais metas infinitas seriam, segundo Husserl, tal como um telos espiritual desta nova humanidade (uma vivência intelectiva originária que dominaria todas as mudanças de formas europeias, conferindo-lhe o sentido de uma evolução em direção a um polo eterno). Trata-se, portanto, não de uma evolução biológica, que conduz, em graus sucessivos, os organismos individuais do embrião à maturidade, do nascimento à morte ("Essencialmente, não há uma zoologia dos povos") (Husserl, [1936] 1976, p. 320), mas, 
antes sim, de uma evolução espiritual por intermédio da qual o conjunto da humanidade europeia se unificaria - não pela simples justaposição de diferentes nações, que somente se influenciam pela filiação, pelo comércio, nos campos de batalha - mas pelo novo espírito de livre crítica orientado para tais metas infinitas. Segundo a interpretação husserliana, a filosofia assumiria a sua função diretriz, tornando-se responsável pela "saúde espiritual" da humanidade europeia.

Aos olhos de Husserl, se esta humanidade europeia mergulhou em uma profunda crise a partir da Primeira Guerra, foi fundamentalmente porque esta mesma humanidade - ao exaltar o conhecimento matemático da natureza e do mundo em geral, estendendo-o ao conhecimento do espírito, também concebido como "objetivamente no mundo e como tal fundado na corporalidade" (Husserl, [1936] 1976, p. 341) - sucumbiu a um esquecimento da própria filosofia, considerada, na análise husserlinana, a forma cultural que, desde o seu surgimento, se tornou responsável por unir, por relações somente espirituais, o povo europeu (para além das diferenças de tipos de humanidades e de cultura). Tomadas por este esquecimento, sobretudo, a partir da Primeira Guerra, as nações europeias passaram a acirrar o ódio e a destruíção. Porém, como afirma Husserl, por mais hostilizadas que estejam entre si, tais nações conservam um peculiar parentesco no plano espiritual que as transcende em suas diferenças nacionais. Nos termos de Husserl: "É algo como uma irmandade que nos dá, nesta esfera, uma consciência pátria" (das Bewusstsein einer Heimatlichkeit) (Husserl, [1936] 1976, p. 320).

Mas, aos olhos de Husserl, a crise vivida pela Europa resulta da alienação da humanidade europeia a um naturalismo funesto, para o qual o homem não é senão um "fato natural". Segundo Husserl, os próprios cientistas do espírito pouco poderiam auxiliar essa humanidade em meio a este cenário de crise, uma vez que não abdicam de estender este mesmo objetivismo naturalista para o domínio das ciências do espírito. Daí Husserl dizer, uma vez mais, 
em tom de alerta, o que fora uma das suas principais preocupações ao longo das primeiras décadas do século XX: "É um cotrassenso considerar a realidade do espírito como um anexo real dos corpos, atribuindo-lhe um ser espaço temporal dentro da natureza" (Husserl, [1936] 1976, p. 342). A aceitação de tal objetivismo naturalista implicaria, segundo Husserl, em uma "unilateralidade ingênua" (naive Einseitigkeit): contraditória teoréticamente e perigosa para a humanidade europeia. Para Husserl, tal visão naturalista do mundo e do homem, ao relegar à vida espiritual (criadora de formas culturais) um sentido meramente "fisiológico", se tornou a principal responsável por restringir esta humanidade a uma "humanidade de fatos", fomentando, junto a ela mesma, o referido esquecimento da filosofia.

Para remediar tal estado de adoecimento espiritual no qual se encontrava o homem europeu seria necessário, mais do que nunca, conforme Husserl já propunha desde 1907, nas Cinco Lições, denunciar o contrassenso no qual invitavelmente incorreria o naturalista, bem como os problemas de fundamentos resultantes do projeto de naturalização da vida do espírito. Denunciando, uma vez mais, tais problemas de fundamentos, bem como os perigos que tal doutrina naturalista representaria para a cultura europeia, enquanto um "filósofo a serviço da humanidade", Husserl não hesita em convocar essa humanidade a reviver o que foi esquecido, fazendo renascer das cinzas a experiência de uma "racionalidade efetiva" (wirklichen Rationalität) que, ao triunfar sobre o naturalismo, uma vez mais, uniria esta mesma humanidade europeia em meio a um cenário de crise e devastação.

\section{Considerações finais}

A consideração dos dois períodos do itinerário husserliano abordados no presente artigo permite-nos notar que a crítica de Husserl ao naturalismo coloca-nos, ao menos, frente a duas denúncias cruciais: a primeira delas é de ordem puramente teorética, ao passo que a segunda remete-nos para uma discussão políticosocial, no 
âmbito da cultura europeia. Conforme vimos, no primeiro período abordado, de 1900 a 1911, Husserl alerta-nos para a seguinte implicação da consideração naturalista: a de que todo pensamento que tenha como base a doutrina do naturalismo incorre, inevitavelmente, em um contrassenso teórico e, por conseguinte, em um ceticismo que se autocontradiz. Já no período de 1923 e 1935, como pudemos acompanhar, Husserl concentra-se em denunciar os impactos de tal modo de consideração sobre a formação da mentalidade do homem europeu, propondo-nos um diagnóstico das razões mais profundas da crise que se instaurou na cultura europeia a partir da Primeira Guerra. Tais denúncias encontram-se indissocialvelmente ligadas. Afinal, ao dar às costas para os problemas de fundamentos nos quais o naturalismo e, sobretudo, o projeto de naturalização da consciência, incorria, esta mesma humanidade europeia fomentava uma posição perante o mundo, na qual a própria filosofia econtrava-se cada vez mais próxima de se esvair em um objetivismo naturalista. Em um mundo reduzido a uma realidade de fatos naturais, esta humanidade de fatos não tardaria em justificar suas decisões com base em proposições extraídas dos fatos e, portanto, inferidas a partir da observação positiva dos mesmos. Tais proposições - enquanto generalizações da experiência não perderiam o seu cariz episódico ou contingente. O pensamento estaria, portanto, destinado a um desamparo irreversível, uma vez que, por mais êxito que obtivesse, em meio à exaltação do objetivismo naturalista, o próprio pensar - restrito a inferências de proposições empíricas - não poderia apreender conteúdos cuja validade estivesse inteiramente livre do assédio do que é contingente. Esvaída em um naturalismo generalizado, a filosofia estaria na iminência de seu fim e a humanidade europeia mergulharia, inevitavelmente, em um estado de barbárie e destruição. Apesar de suas convicções, Husserl parece pressentir que a crítica ao naturalismo pode permanecer inaudita por esta mesma humanidade cujo adoecimento espiritual é manifesto. Afinal, como ele próprio nos diz, na mesma conferência de 1935, "a situação nunca melhorará 
enquanto não se colocar em evidência a ingenuidade do objetivismo" (Husserl, [1936] 1976, p. 345) e não nos convencermos do absurdo de considerar a natureza e o espírito como realidades de sentido homogêneo. Tal ingenuidade do pensamento natural teria, portanto, um duplo aspecto: alimentar, sem se aperceber, um contrassenso teórico, além de renovar uma posição perante o mundo, cujo perigo logo se faz notar no seio da humanidade europeia. Mais do que nunca, ao denunciar tais aspectos da referida ingenuidade, enquanto "observador desinteressado", a figura do filósofo renasce para redimir esta humanidade da sua própria incredulidade em uma "racionalidade efetiva", para redimi-la, enfim, do esquecimento da própria filosofia, forma cultural a partir da qual se anuncia, aos olhos de Husserl, o sentido originário da vida espiritual do homem europeu.

\section{Referências}

DELACAMPAGNE, C. Histoire de la Philosophie au XX Siècle. Paris: Seuil, 1995.

HUSSERL, E. Logische Untersuchungen. Erster Band. Prolegomena zur reinen Logik (1900). Halle a.d.S.: M. Niemeyer, [1900] 1913.

HUSSERL, E. Die Idee der Phänomenologie. Fünf Vorlesungen. (1907) Husserliana. Band II. Netherlands: M. Nijhoff, 1950.

HUSSERL, E. Philosophie als strenge Wissenschaft. Logos: Zeitschrift für systematische. Philosophie/Logos, 1910-1911, 53, p. 289-341.

HUSSERL, E. Erneuerung. Ihr Problem und ihre Methode (1923). In: HUSSERL, E. Aufsätze und Vorträge (1922-1937). Husserliana. Band XXVII. Dordrecht; Boston; London; Kluwer Academic Publishers, 1989. 
HUSSERL, E. Die Krisis des europäischen Menschentums und die Philosophie (1936). Husserliana. Band VI. Netherlands: M. Nijhoff, 1976.

KELKEL, A. L.; SCHÉRER, R. Husserl: sa vie, son oeuvre avec un exposé de sa philosophie. Paris: Presses Universitaires de France, 1964.

MORUJÃO, A. F. Husserl e a filosofia como ciência de rigor. In: MORUJÃO, A. F. Estudos Filosóficos - Vol. I: estudos gerais. Lisboa: Imprensa Nacional - Casa da Moeda, 2002. (Série Universitária).

TOURINHO, C. D. C. A "concessão dolorosa” de Husserl na segunda edição de Prolegômenos: a ideia de verdade em si. Revista de Filosofia Aurora. v. 29, n. 39, 2014, p. 563-580.

Artigo recebido em 22/06/2016, aprovado em 18/08/2016 